\title{
Proposal of a Process of Mass Customization of Kitchen Cabinetry
}

\section{SIGRADI2018 TECHNOPOLITICAS \\ xxii congresso da sociedade iberoamericana de gráfica digital 22th conference of the iberoamerican society of digital graphics $07|08| 09 \mid$ novembro|2018 iau usp | são carlos | sp br}

\author{
Miguel Pereira Stehling \\ Universidade Estadual de Campinas-UNICAMP | Brazil | miguelstehling@hotmail.com
}

Regina Coeli Ruschel

Universidade Estadual de Campinas-UNICAMP | Brazil | ruschel@fec.unicamp.br

\begin{abstract}
Digital Fabrication has been widely used for the production of standardized building components, but not so in the engineered-to-order fabrication strategy, a system in which the customer's needs are fulfilled in the design stage. Mass Customization meets the demands of a customer at a cost near that of Mass Production. This study presents the current stage of an Action Research dealing with Mass Customization, design and BIM adoption challenges, proposing the adoption of BIM aiming Mass Customization at engineered-toorder systems for Small and Medium Enterprises. It uses Web-based User Interface and Revit and Dynamo models exported to Computer Numerical Control machines.
\end{abstract}

Keywords: Mass customization; Engineered-to-order; Digital fabrication; Prefabrication; BIM.

\section{INTRODUCTION}

Engineered-To-Order (ETO), according to Haug et al. (2009), is a manufacturing system of "...products which are engineered to the specific requirements of the customer". Eastman et al., (2008, p. 246) also define ETO as "...any component customized to fit a specific location and fulfill certain building function". It is the design, fabrication, and assembly of a one-of-a-kind product, a system in which the customer's need is fulfilled as early as in the design phase. Engineered-to-order operation is typical for small and medium-sized companies. ETO components specifications are more demanding and more vulnerable to ineffective sharing of information between site and factory, therefore, they are more managementintensive. Custom kitchens, structural steel frames, structural pre-cast concrete, HVAC duct parts prefabricated off-site, curtain wall and facade panels are some ETO examples. As identified by Swierczek and Kisperska-Moron (2016), companies within the ETO manufacturing system, are the ones that deliver highly customized products.

Digital Fabrication, according to Gattas and You (2015) relates to technologies that can be used to manufacture building components from automated workshop machines such as Computer Numerical Control (CNC) routers or laser-cutters. In the process of integration between Computer Aided Design (CAD) and Computer Aided Manufacturing (CAM), the production of standardized building components through automated machines have become widely adopted. But not so, in engineered-toorder fabrication strategy, because, as reported by $\mathrm{De}$ Leon et al. (2013), CNC machines require considerable efforts and expertise in the set up and programming process, before bringing the machine into production. According to Shelden (2014), the proliferation of affordable computing has transformed the capability of architecture to deal with complex forms and details. Although the architecture is going through a deep transition, there still remains a deep discrepancy between the overflow of digital information and the limits on digital fabrication.

Mass Customization (MC), in the opinion of Kieran and Timberlake (2004), is a hybrid of customization and mass production. MC is a process that proposes automated fabrication with the ability to differentiate each product from those that are fabricated before and after it, and with costs near to that of Mass Production. And Stralen (2015) states that the potential for customization can be increased by shifting the project's focus from the object to processes. According to Farr et al. (2014), Mass Customization denotes an offering that meets the demands of each custumer, but can be produced with the Mass Production efficiency, low-cost and high volume. Khalili-Araghi and Kolarevic (2016) say that the roots of MC date back to 1970 when Alvin Toffler asserted in his book Future Shock that future technologies would be capable of providing customized products with prices almost to those of standardized products.

A manufacturing system was described by Lampel and Mintzberg (1996) as a four stage process: Design, Fabrication, Assembly, and Distribution. As represented in Figure 1, each stage can be standardized or customized giving rise to five different strategies that range from Pure Customization to Pure Standardization. As described in Table 1, Pure Customization is when each stage is customized, and Pure Standardization is when each stage is standardized and not a single customer's need is fulfilled. Therefore, according to this criteria, companies that offer Mass Customization can do it in four levels: The lower MC level corresponds to the Segmented Standardization, where only the Distribution stage is customized. The second level of MC is the Customized Standardization, that offers customization in the Assembly and Distribution stages. The third MC level is the Tailored Standardization, that offers customization in Fabrication, Assembly, and Distribution, and finally, the upper level the 
Pure Customization that offers customization in all four stages of the manufacturing process.

Table 1: A description of the manufacture strategies by Lampel and Mintzberg (1996).

\begin{tabular}{|c|c|}
\hline Strategy & Description \\
\hline $\begin{array}{l}\text { Pure } \\
\text { customization }\end{array}$ & $\begin{array}{l}\text { The product is engineered-to-order. The } \\
\text { design is made to the customers } \\
\text { specifications. }\end{array}$ \\
\hline $\begin{array}{l}\text { Tailored } \\
\text { customization }\end{array}$ & $\begin{array}{l}\text { Small modifications are made to a } \\
\text { standard design to adapt it to the client's } \\
\text { needs. Only the fabrication, assembly and } \\
\text { distribution are customized. }\end{array}$ \\
\hline $\begin{array}{l}\text { Customized } \\
\text { standardization }\end{array}$ & $\begin{array}{l}\text { Customized products are assembled from } \\
\text { a range of available standardized } \\
\text { components or modules. Only the } \\
\text { assembly and distribution are customized. }\end{array}$ \\
\hline $\begin{array}{l}\text { Segmented } \\
\text { standardization }\end{array}$ & $\begin{array}{l}\text { A basic design is modified anticipating } \\
\text { trends and offering various options, but } \\
\text { not individual choice. Only the distribution } \\
\text { is customized. }\end{array}$ \\
\hline $\begin{array}{l}\text { Pure } \\
\text { standardization }\end{array}$ & $\begin{array}{l}\text { Customers must choose amongst } \\
\text { standard products offered. The entire } \\
\text { manufacturing process is standardized. }\end{array}$ \\
\hline
\end{tabular}

In the opinion of Farr et al. (2014), Web-based databases can be expected to be helpful tools together with Building Information Modeling (BIM) for facilitating mass customization in the Architecture, Engineering and Construction (AEC) industry. Khalili-Araghi and Kolarevic (2016) pointed out that dimensional customization and design validation could be examined through interactive website platforms matching customer preferences with product specification, technical issues related to the system interface and personnel skills to perform design tasks. Farr et al. (2014) concluded also that researches need to address web-based applications with easy to use and user friendly Graphical User Interfaces. And Luth(2011) adds that if everyone operates on the same database, there is no need for interoperability. Luth says that the current IFC schema has served the purpose of interoperability, but it is "bogged down" with representations of database objects. Also concerning to web interfaces, in January of 2015, there was, at the Toronto Pearson International Airport, Canada, a sign that read: "In the future, export will be transmitted, not transported". This statement suggests the internet as a mechanism capable to improve the design and production process of fabrication of building components

Khalili-Araghi and Kolarevic (2016) stated that customers want to purchase homes individualized according to their needs, but homebuilders want to maintain standardized designs and processes in order to maintain the efficiency of their systems. BIM allows a trade-off between customization and standardization providing the benefits from both strategies. According to Eastman et al. (2008), BIM encompasses a virtual model carrying accurate geometry, and relevant data needed to support the fabrication of building components. These characteristics provide the means to manage the vast amount of information required of mass customization, because, as Neuman et al. (2015) stated, customized products have more complex design, engineering, fabrication and installation requirements.

Especially for subcontractors and fabricators, Eastman et al. (2008) stated that BIM supports a collaborative process for the development of conceptual design and fabrication detailing allowing essential changes in processes. Therefore, the problem identification in this research arises from the interest of the researcher to find a solution to practical problems faced by engineer-toorder manufacturers, specifically in their processes. Some of the problems are: (1) Low productivity in the process of detailed design for Digital Fabrication; (2) Lack of knowledge of BIM impact in Digital Fabrication in the context of Mass Customization; (3) Lack of knowledge in implementing BIM in small firms of design and manufacturing of customized products; (4) Lack of integration between customer preferences and product specification and detailing for fabrication; (5) Most of their labor effort is spent producing and updating documents, increasing the indirect costs; (6) The same information is registered into computers several times, each time for a distinct use; (7) Rework is routine and project lifecycles are long.

The main objective is through an action research, the development of artifacts for BIM adoption integrated to MC strategy for subcontractors and fabricators in the woodworking industry, specifically of custom kitchens and other cabinetry. One of the objectives of this investigation

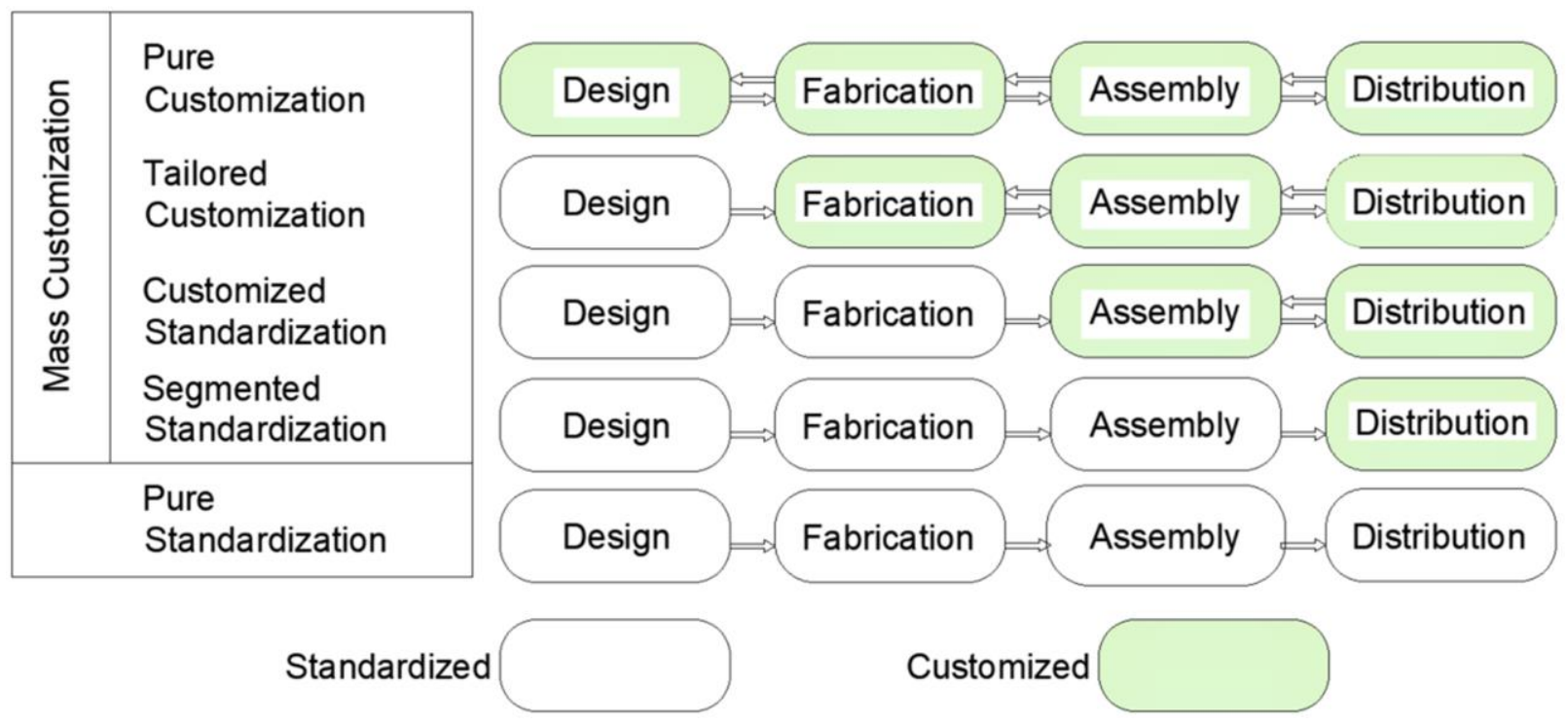

Figure 1: The manufacturing strategies, adapted from Lampel and Mintzberg (1996) 
is to propose artifacts for the solution of problems of "Small and Medium Enterprise" (SME).

\section{METHODOLOGY}

Gil (2010) and Adelman (1993) define Action Research as an empirical method conceived for reflection, discussion and decision, carried out in close relation with action to develop interventions to solve a problem or improve a specific environment. The researcher and participant engage collaboratively through a cyclical process.

This study presents the current stage of an Action Research aiming to design, develop and evaluate artifacts for BIM adoption integrated to Mass Customization strategy for subcontractors and fabricators of custom kitchens. In the first cycle of the Action Research, meetings with key personnel in the studied company have been held. In those meetings, guidelines for the research were drawn and after that, a Web-based Graphical User Interface using HTML/PHP with MySQL database has been already developed as well as some kitchen component families for the Revit modeling. This Action Research is within the bigger scenario of a Design Science Research of a doctoral thesis. The thesis will propose some artifacts useful in the processes of the fabricators of building components who currently work within the engineered-to-order system and that are aiming at Mass Customization. It encompasses the Design stage using a Web-based Graphical User Interface linked to a BIM model created with Revit and Dynamo, as well as the Fabrication stage using the BIM model exported to the CNC machines.

The research is being accomplished in a collaborative manner in the context of a small fabricator of engineeredto-order components, specialized in design and production of custom kitchens and other cabinetry. Although an action research does not study the subjects' previous experiences, but the current experiences, the researcher's knowledge of the company's operation is allowing him to be more participative and interpretative. The researcher plays an active role in the studied company, having a good knowledge of his colleagues' practices. The protocol for the research is summarized in Table 2.

Table 2: Protocol for the research.

\begin{tabular}{ll}
\hline Item & Description \\
\hline Research & The researcher, the firm's CEO, design \\
participants. & and production engineers, the CAD \\
& manager, the database administrator, and \\
& the CNC programmer.
\end{tabular}

Approach. Qualitative, verbal description of the phenomena observed.

Steps to be Plan / design;

performed Act / development

Observation / Evaluation

Reflection / lessons learned

Analyse and Participant observation, interviews, and interpretation of project's documents.

data

\section{RESULTS}

The research is being conducted in two cycles of four stages each, shown in Figure 2 and described below:
The first stage of the first cycle was a reflection conducted through an analysis of the results of a case study performed prior to this investigation.

In the second stage of the first cycle, a process of customized design and fabrication have been proposed as an artifact to the developed. This process is a method mediated by BIM, and the BIM adoption strategy was planned as well. Also, techniques and tools for the development and evaluation of the artifacts were chosen. A model is also proposed using the concept of "engineering continuum" developed by Luth (2011) whereby the definition of design and construction engineering are symmetrical and differ only in emphasis; Luth says that engineering is a continuum with elements of design and construction throughout the project's lifecycle. The proposed model and method follow Luth's concept that a universal database schema will be a seminal event in the design and construction industry for the twenty-first century, and there is a need for a simplified method for the database of the building

The third stage of the first cycle comprised the preliminary test of the method and the tools. It was performed through the design and digital fabrication of a limited scope of kitchen components. Just a few base cabinets with parameterized drillings. This research stage approaches the concept of Bock (2015), whereby the construction automation is still in an innovation phase occurring extremely slowly due to complexities of products and low $R \& D$ budgets. This research is concerned with the adaptation of products, processes and the organization so that the concept of Robot-oriented design may be applied through the use of Generative Design with Digital Fabrication and also through some adjusting in the conventional fabrication process.

The fourth stage of the first cycle will be the evaluation of the first cycle, to be performed with the staff of the studied firm.

The first stage of the second cycle will be the expression of lessons learned in the first cycle and reflections about the operationalization of the manufacturing model and process proposed through Product Families. According to Schneider (2014), a Product Family is a combination of a generic product structure with a set of variables and a set of constraints over some of those variables. Product Families are designed in such a way that allows flexibility in the creation of a product consistent with the customer requirements while ensuring that no constraint is violated. Box with fronts, Open box, Doors, Drawers, Crown, Valances are some example of Product Families to be created in this Research.

The second stage of the second cycle are the plan/design of the artifacts, indicating techniques and tools tested in the first cycle. Also, the detailed information on the artifacts' requirements, the artifacts' internal characteristics, the context in which it will operate, its limits and relations with the external environment. Procedures for the development and evaluation of the artifacts will be described, as well as its expected performance. These assertions are to ensure the accuracy of the research allowing it to be replicated and confirmed.
3 
In the third stage of the second cycle the artifacts will be developed based on the lessons learned in the first cycle. The researcher, collaboratively with the studied firm's assigned personnel, will build the internal environment of the artifact. Several approaches will be utilized such as computational algorithms, web-based databases, graphical representations, and BIM models.

In the fourth stage of the second cycle, the artifacts will be evaluated. The researcher, as a participant observer, will measure the artifacts' behavior in regard to the solution of the problem. This evaluation will be performed in an experimental environment in a real context. If the artifact does not meet the previously defined requirements, the researcher will identify the shortage, and prescribe measures to resume another research where the shortage happened.

By the adoption of BIM in the design and fabrication operation of custom kitchens, it is expected an impact both on process and people. The results expected are not only the adoption of new software but also new workflow and processes. The strategy that is being developed through this research goes beyond the development of software, the acquiring of hardware and training the staff. It is being developed a thorough plan aiming to get the staff involved and committed from the early stages of the process.

The BIM adoption strategy contains four stages that intercept each other and are described in Figure 3 . The first stage is setting measurable goals considering the desired benefits, the level of detail required for design and fabrication, how, when and by whom the components library will be created, the information flow and the integration with management systems. The second stage takes into consideration the planning and scheduling of the activities, the commitment of the personal and the pace of change. The third stage takes into account the development and customization of software, the creation of Revit components library and acquisition of the necessary hardware for replacement of existing CAD workstations to BIM workstations, and the fourth stage considers the staff training with the necessary skills in order to ensure their commitment and the assigning of the right person to each new role.

In order to smooth the process of adoption BIM among SME, the choice of Revit/Dynamo for the BIM models, and HTML/PHP and MySQL for the web database application, took into consideration the following aspects: First, these are the most worldwide used tools with plenty of resources available on the web for training the staff; Second, there are plenty of specialists in those tools,

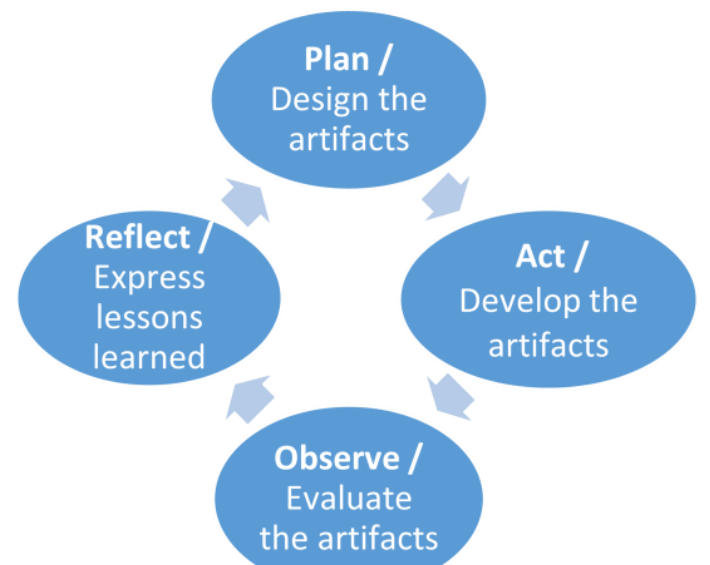

Figure 2: Design, development and evaluation of artifacts. which makes it easier for the hiring process. The third aspect is their joint ability to provide an interface between design and fabrication and generation of CNC machinery instructions. As the fourth aspect, HTML/PHP and MySQL are open sources and the standard tools to build webbased databases. HTML is a straightforward programming language having a short learning curve. MySQL is a Relational Database Management System that uses SQL languages. PHP provides the interface between HTML and MySQL.

Figure 3: BIM adoption strategy for custom kitchens manufacturing. Source: Authors.

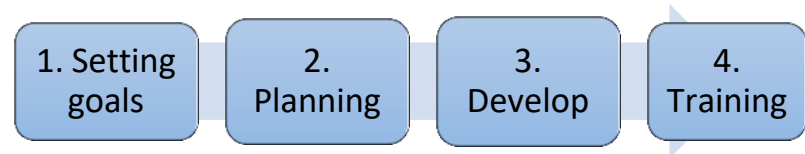

The interoperability between the BIM models and the CNC machines is currently an issue due to the fact that CNC machines are built with proprietary programmable logic controllers. Efforts to smooth this process have been made through the development of a system entitled STEP-NC, but a fully interoperable system is still a long way to go. This research is tackling this issue and uses a BIESSE Rover CNC router machine, that can read DXF, CIX, CID and NC code files.

\section{DISCUSSION}

In current practice, many building parts are already fabricated off-site, and among these, it's increasing the use of the digital fabrication process. As stated by KhaliliAraghi and Kolarevic (2016), customers want to buy individualized homes, but designers and builders want to maintain standardized products in order to keep the efficiency of their systems. In this context, the contribution of this research is the formulation of a solution that enables reconfiguration of fabricators structures and processes into BIM mediated mass-customized production system for SME. Such solution will provide knowledge on how to determine the appropriate level of customization on a specific product addressing the following issues for SME: (a) the value placed on a level of customization by the customers' requirements, (b) the system's ability to deliver that level of customization, and (c) the combination of these apparently conflicting issues.

The formulated solution will impact the design and fabrication process and people, reducing design coordination conflicts and the efforts and expertise required in the set up and programming process of CNC machines, before bringing them into production. Designs will be made to the customers specifications as clients will be allowed to make late changes. The solution goes beyond new software adoption, hardware and staff training. It's a thorough plan that gets staff and clients involved and committed from the design stage of the process. 
Neuman et al. (2015) stated that engineered-to-order products usually require more detailed specification for the purchase of materials. Therefore, the automated production of bill of materials provided by the proposed process will reduce the costs of engineering, detailing and rework.

BIM adoption in Engineered-To-Order systems will provide more reliable information and automated generation of codes for CNC machines, therefore, reducing the human labor necessary to set up these machines. As a result, automation in building components manufacturing will be increased, and prefabrication and preassembly can be improved because parts fit properly.

\section{REFERENCES}

Adelman, C. (1993). Kurt Lewin and the Origins of Action Research,Educational Action Research, 1(1), 7-24, DOI: 10.1080/0965079930010102. ISSN: 0965-0792 (Print) 17475074 (Online) http://www.tandfonline.com/loi/reac20

Bock,T. (2015). The future of construction automation: Technological disruption and the upcoming ubiquity of robotics, Automation in Construction, 59, 113-121, https:doi.org/10.1016/j.autcon.2015.07.022

De Leon, A.P., Burry, J.,Davis, D, Williams, N, Burry, M., Wilson, M.. (2013). A Flexible Automated Digital Design For Production Workflow,Proceedings Of The 18th International Conference On Computer-Aided Architectural Design Research In Asia, 643-652, The Association for ComputerAided Architectural Design Research in Asia (CAADRIA) ,Hong Kong ,and Center for Advanced Studies in Architecture (CASA).

Eastman,C.M., Teicholz,P., Sacks,R., Liston, K. (2008). BIM handbook: A guide to Building Information Modeling for owners, managers, designers, engineers, and contractors, Hoboken, NJ, John Wiley \& Sons, Inc, ISNB:978-0-47018528-5

Farr, E.R.P., Piroozfar, P.A.E.;Robinson, D. (2014). BIM as a generic configurator for facilitation of customisation in the AEC industry, Automation in Construction, 45, 119-125, https://doi.org/10.1016/j.autcon.2014.05.012

Gattas, J.M.,You, Z.(2016). Design and digital fabrication of folded sandwich structures, Automation in Construction, 63, 79-87, https://doi.org/10.1016/j.autcon.2015.12.002
Gil, A.C. (2010). Como elaborar projetos de pesquisa, São Paulo, SP, Editora Atlas, ISBN 978-85-224-5823-3, 4Ed.

Haug, A., Ladeby, K., Edwards, K. (2009). From engineer-toorder to mass customization, Management Research News, 32(7) 633-644, DOI: 10.1108/01409170910965233

Khalili-Araghi,S., Kolarevic,B. (2016). Development of a framework for dimensional customization system:A novel method for customer participation, Journal of Building Engineering, 5 , 231-238, https://doi.org/10.1016/j.jobe.2016.01.001

Kieran,S.;Timberlake,J. (2004). Refabricating Architecture, New York, NY,McGraw-Hill, ISBN 0-07-143321-X

Lampel,J., Mintzberg,H. (1996). Customizing Customization, Sloan Management Review, 38(1), 21-30

Luth,G.P. (2011). VDC and the Engineering Continuum,Journal of Construction Engineering and Management, 137(10), 906915, https://doi.org/10.1061/(ASCE)CO.1943-7862.0000359

Newman,S.T., Nassehi, A, Xu,X.W., Rosso Jr, R.S.U., Wang,L., Yosof, Y., Ali,L, Liu,R., Zheng, L.Y., Kumar,R., Vichare, P., Dhokia, V. (2014). Strategic advantages of interoperability for global manufacturing using CNC technology, Robotics and Computer-Integrated Manufacturing, 24 (6) 699-708, https://doi.org/10.1016/j.rcim.2008.03.002

Schneider, H. M.(2014). Setting Up A Backtrack-Free Customisation Process For Product Families: Estabelecendo Um Processo De Customização Livre De Retrocessos Para Famílias De Produtos,Campinas, SP, Universidade Estadual de Campinas, Programa de Pos-Graducacao em Engenharia Eletrica, http://repositorio.unicamp.br/jspui/handle/REPOSIP/261226

Shelden, D.R. (2014). Information, Complexity and the Detail,,,Architectural Design, 84(4), 92-97, Special Issue: Future Details of Architecture, https://doi.org/10.1002/ad.1786

Swierczek, A., Kisperska-Moron, D.(2016). The role and attributes of manufacturing companies in virtual supply chains, The International Journal of Logistics Management, 27(2), 511-532, ISSN: 0957-4093, https://doi.org/10.1108/IJLM-12-2013-0162

Stralen,M.,V.(2015). The machine for living in the conversational age, Kybernetes, 44(8/9), 1388 -1396, Subject Area: Information \& Knowledge Management, ISSN:0368-492X, https://doi.org/10.1108/K-11-2014-0241, Emerald Group Publishing Limited 